\section{Cho Receives Von Hippel Award}

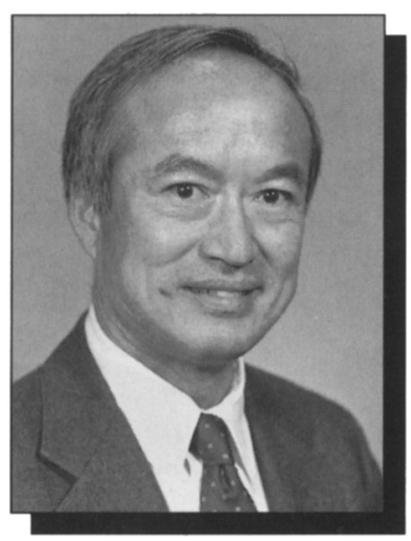

The Von Hippel Award, the Materials Research Society's highest honor, this year goes to Alfred Y. Cho, director, Semiconductor Research Laboratory at AT\&T Bell Laboratories. He received the award "for pioneering work in the development of molecular beam epitaxy (MBE) and its application to new devices based on quantum wells and artificially structured materials." The Von Hippel Award is given annually to an individual in recognition of outstanding contributions to interdisciplinary research on materials.

Al Cho has made seminal contributions to materials science and physical electronics through his pioneering development of the molecular beam epitaxy (MBE) crystal growth process. He took the emerging, somewhat esoteric process of MBE-a method for precisely controlling compositional profiles at the monolayer level-and turned it into a process of great scientific and technological significance. He demonstrated that MBE could be used to prepare epitaxial films with exquisite control and showed that these films could be the basis of devices with exceptional properties. His work has bridged many disciplines ranging from fundamental surface science, through epitaxial crystal growth, to device fabrication and testing.

The capabilities of MBE have allowed new fields of materials research to develop. For example, the ability to precisely make quantum wells has had far-reaching impact from demonstrations of classroom physics to revolutions in laser devices for the electronics, information, and communications industries.

Cho laid the foundations for the MBE process in the early 1970s through his use of in situ monitoring of semiconductor crystal growth and epitaxy of GaAs. He was the first to observe the two-dimensional high-energy electron diffraction pattern of GaAs crystal growth, and the smoothing of the crystal surface, which ultimately formed the basis for successful growth of MBE materials and artificial structures. Beyond III-V materials, MBE also can be used for epitaxial growth of $\mathrm{Si}, \mathrm{Ge}$, metals, and insulators.

The ability to form perfect alternating layers of $\mathrm{GaAs}$ and $\mathrm{AlGaAs}$ has led to the fabrication of modulation-doped superlattices with ultra-high electron and hole mobility which make the fastest transistors (as high as $140 \mathrm{GHz}$ ).

Cho is responsible for many "firsts." In 1971, he fabricated the first MBE superlattice, and several years later created the first MBE microwave device-a GaAs voltage varactor. Among other devices he has developed using MBE are the IMPATT diode, field-effect transistors operating at microwave frequencies, lownoise mixer diodes used in radio astronomy, MBE double-heterostructure injection lasers operating continuously at room temperature, and heterostructure devices such as tunneling transistors based on bandgap engineering.

Cho's open and generous personality expedited worldwide acceptance of MBE. Despite skepticism in the technological community, he refined the technique and shared information with all who would listen, not holding back details. He collaborated with device people at Bell Labs and with equipment manufacturers to make sure his new ideas were given a chance. As a result, MBE is broadly used for advanced multilayer crystal growth and has led to radically new devices, including high-speed transistors, microwave devices, light emitters and lasers, and detectors. Most of the semiconductor lasers used in today's compact disk players are manufactured using MBE-grown material.

The impact of $\mathrm{MBE}$ on fundamental science has been at least as dramatic as its impact on semiconductor technology. A significant contribution of MBE is the experimental generation of low-dimensional systems. An entirely new state of electrons (the fractional quantized Hall effect) was observed, which required high-quality semiconductor material as can be grown by MBE.
$\mathrm{Al}$ Cho received his $\mathrm{BS}, \mathrm{MS}$, and $\mathrm{PhD}$ degrees in electrical engineering from the University of Illinois in 1960, 1961, and 1968, respectively. In 1961, prior to obtaining his PhD degree, he worked at Ion Physics Corporation, a subsidiary of High Voltage Engineering Corporation. He joined TRW-Space Technology Laboratories in 1962, where he researched physical electronics. He joined Bell Laboratories in 1968 as a member of the technical staff in the Materials Science Research Department of the Solid State Electronics Research Laboratory and became head of the Electronic and Photonic Materials Research Department in 1984. He then became director of the Materials Processing Research Laboratory at AT\&T in 1987, and started in his current position as director of the Semiconductor Research Laboratory in 1990.

Cho has received numerous awards and honors, including the National Medal of Science, the IEEE Medal of Honor, and elections into the National Academy of Science and the National Academy of Engineering. In addition, he received the Electronics Division Award of the Electrochemical Society in 1977, the APS International Prize for New Materials with J.R. Arthur in 1982, the Morris N. Liebman Award of IEEE in 1982 , the International GaAs Symposium Award with the Heinrich Welker Medal in 1986, the Solid State Science and Technology Medal of the Electrochemical Society in 1987, the Gaede-Langmuir Award of the American Vacuum Society in 1988, the Achievement Award of the Industrial Research Institute in 1988, the New Jersey Governor's Thomas Alva Edison Award in 1990, and the American Association for Crystal Growth's International Crystal Growth Award (with M.B. Panish) in 1990. Cho is also a member of the American Academy of Arts and Sciences and is an IEEE and APS fellow. He has more than 375 publications to his name and holds more than three dozen patents.

The Von Hippel award will be presented to Cho at the 1994 MRS Fall Meeting during the awards ceremony on Wednesday, November 30, at 6:00 p.m. in Salon E of the Boston Marriott Hotel. Cho will then give a lecture on molecular beam epitaxy, which will be followed by a wine and cheese reception. 